\title{
The Genetics of Ultra-Rare Renal Disease
}

\author{
Melissa Muff-Luett ${ }^{1} \quad$ Carla M. Nester ${ }^{2,3}$ \\ ${ }^{1}$ Division of Pediatric Nephrology, University of Nebraska Medical \\ Center, Omaha, Nebraska, United States \\ 2 Division of Pediatric Nephrology, Dialysis and Transplantation, Stead \\ Family Department of Pediatrics, University of lowa, lowa City, lowa, \\ United States \\ ${ }^{3}$ Molecular Otolaryngology and Renal Research Laboratory, University \\ of lowa, lowa City, lowa, United States \\ J Pediatr Genet 2016;5:33-42.
}

\begin{abstract}
Address for correspondence Melissa Muff-Luett, MD, Division of Pediatric Nephrology, University of Nebraska Medical Center, 982169 Nebraska Medical Center, Omaha, NE 68198-2169, United States (e-mail: melissa.muffluett@unmc.edu).
\end{abstract}

\begin{abstract}
Keywords

- complement

- atypical hemolytic uremic syndrome

- C3 glomerulopathy

- thrombotic microangiopathy

The complement-mediated renal diseases are a group of ultra-rare renal diseases that disproportionately affect children and young adults and frequently lead to irreversible renal failure. Genetic mutations in alternate pathway of complement genes are pathomechanistically involved in a significant number of these unique diseases. Here, we review our current understanding of the role of genetics in the primary complement-mediated renal diseases affecting children, with a focus on atypical hemolytic uremic syndrome and C3 glomerulopathy. Also, included is a brief discussion of the related diseases whose relationship to complement abnormality has been suspected but not yet confirmed. Advances in genetics have transformed both treatment and outcomes in these historically difficult to treat, highly morbid diseases.
\end{abstract}

\section{Introduction}

Our understanding of the ultra-rare, complement-mediated renal diseases atypical hemolytic uremic syndrome (aHUS) and $\mathrm{C} 3$ glomerulopathy (C3G) has advanced tremendously in the past 10 years. The discovery that genetic abnormalities are central to disease pathology in the majority of patients has been critical to improving patient outcomes. Here, we review the genetic background of the complement-mediated renal diseases and discuss how genetic advances have shaped both our understanding of the underlying pathology and informed treatment options.

\section{Alternate Complement Pathway}

Dysregulation of the alternate complement pathway (AP) is central to complement-mediated renal disease. ${ }^{1-4}$ The AP plays a vital role in innate immunity, remaining constitutively active, and acting as a first-line of defense against microorganisms. The normal activity of the AP requires the complex interaction of an array of proteins. In the complement- mediated renal diseases, normal function of one or more of these proteins is lost. In the case of aHUS, the loss of complement function is often due to a genetic mutation in either a core complement enzyme protein or more commonly in a complement control protein. Less frequently, AP gene mutations also play a role in C3G.

The first protein in the AP is complement component C3 (C3) (-Fig. 1). C3 undergoes spontaneous hydrolysis or can be cleaved by a downstream enzyme known as the $\mathrm{C} 3$ convertase, producing the $\mathrm{C} 3$ breakdown products $\mathrm{C} 3 \mathrm{a}$ (an anaphylotoxin) and $\mathrm{C} 3 \mathrm{~b}$. The cleavage product $\mathrm{C} 3 \mathrm{~b}$ interacts with complement factor $\mathrm{B}(\mathrm{FB})$ to produce a proenzyme (C3bB). FB will be cleaved by complement factor $\mathrm{D}$ (FD) to form the active enzyme, $\mathrm{C} 3$ convertase $(\mathrm{C} 3 \mathrm{bBb})$. The $\mathrm{C} 3$ convertase cleaves additional $\mathrm{C} 3$ into $\mathrm{C} 3 \mathrm{a}$ and $\mathrm{C} 3 \mathrm{~b}$, thus forming an amplification loop of the AP. An additional $\mathrm{C} 3 \mathrm{~b}$ binds with the $\mathrm{C} 3$ convertase to form the $\mathrm{C} 5$ convertase (C3bBbC3b). The $\mathrm{C} 5$ convertase serves to cleave $\mathrm{C} 5$ into $\mathrm{C} 5 \mathrm{a}$, another anaphylotoxin, and $\mathrm{C} 5 \mathrm{~b}$. $\mathrm{C} 5 \mathrm{~b}$ recruits the terminal complement proteins $\mathrm{C} 6$ thru $\mathrm{C} 9$ to form the membrane attack complex (MAC). The MAC forms a transmembrane channel in the wall of an invading received

July 15,2015 accepted

December 2, 2015

published online

February 23, 2016
Issue Theme Genetic Advances in Childhood Nephrological Disorders; Guest Editor: Patrick D. Brophy, MD, MHCDS
Copyright $\odot 2016$ by Georg Thieme Verlag KG, Stuttgart · New York
DOI http://dx.doi.org/ 10.1055/s-0036-1572515. ISSN 2146-4596. 


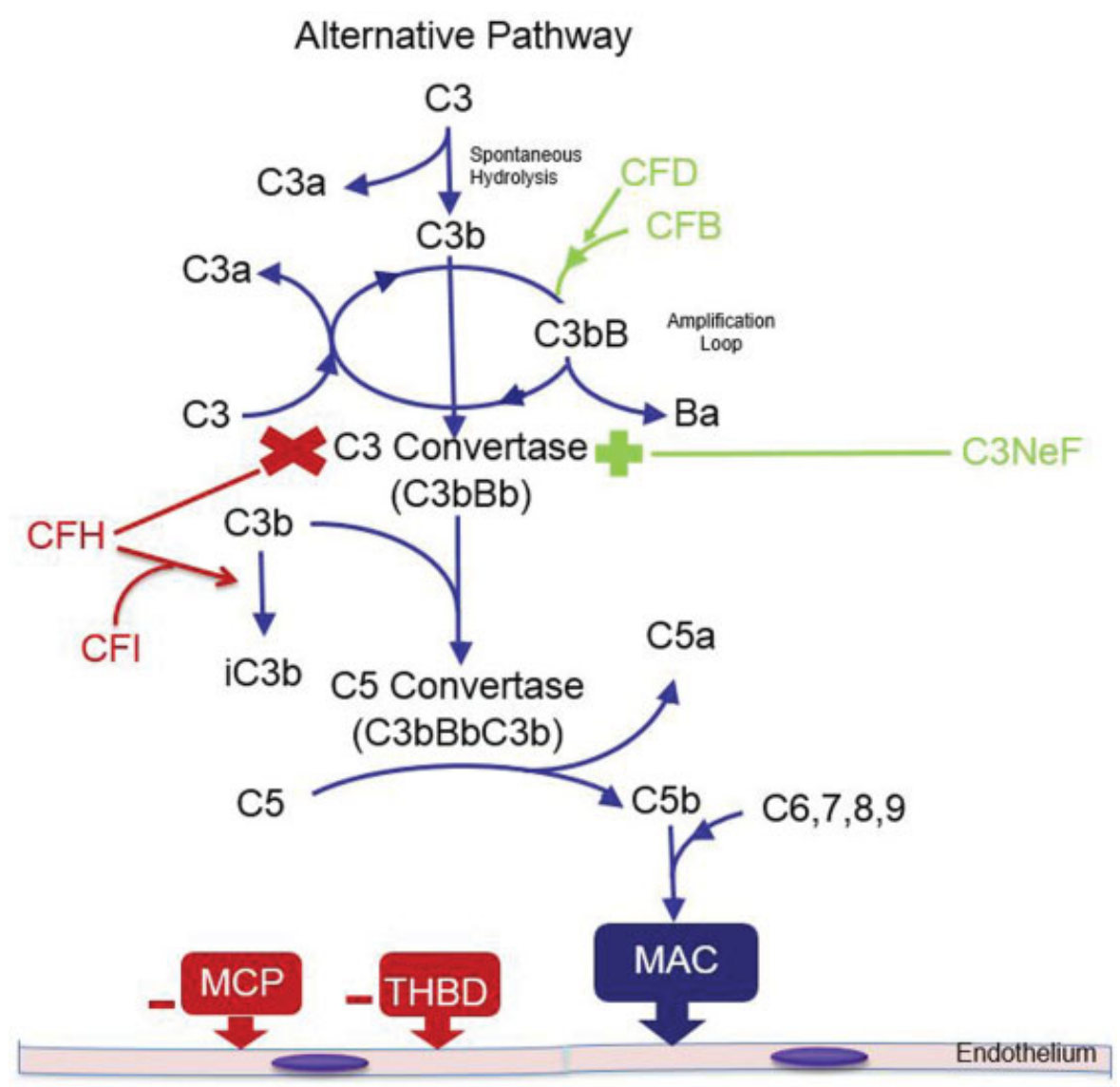

Fig. 1 The alternate complement pathway. The alternative complement cascade is constitutively active. C3 is spontaneously cleaved to C3b which then can enter into the $\mathrm{C} 3$ amplification loop in which $\mathrm{C} 3$ convertase $(\mathrm{C} 3 \mathrm{bBb})$ is generated and subsequently cleaves additional $\mathrm{C} 3$ into $\mathrm{C} 3 \mathrm{a}$ and $\mathrm{C} 3 \mathrm{~b}$ leading to rapid amplification of $\mathrm{C} 3 \mathrm{~b}$. C $\mathrm{C}$ b binds to $\mathrm{C} 3$ convertase to form $\mathrm{C} 5$ convertase (C3bBbC3b) which then enters the terminal complement cascade in which C5 forms $\mathrm{C} 5 \mathrm{a}$, an anaphylotoxin, and C5b which goes on to form the membrane attack complex. Regulation of the alternative complement cascade is controlled with CFH down regulation of the C3 amplification loop and through FI mediated inactivation of C3 to iC3b. Additionally MCP and THBD act to negatively regulate the alternate pathway at the level of the endothelium. These proteins which serve to inhibit the alternative pathway are labeled in red. CFB, which is cleaved by CFD, serve to generate C3 convertase in the C 3 amplification loop. C3NeFs are autoantibodies which stabilize the amplification loop and result in persistent activation of the alternative pathway. The proteins involved in activation of the alternative pathway are labeled in green. C3, complement C3; C3NeF, C3 nephritic factor; CFB, complement factor B; CFD, complement factor $\mathrm{D}$; $\mathrm{CFH}$, complement factor $\mathrm{H}$; CFI, complement factor I; MCP, membrane cofactor protein; THBD, thrombomodulin.

microorganism, disrupting the integrity of its cell wall, leading to cell lysis and death. Self-cells are normally protected from MAC by complement control proteins. When AP control is lost, MAC induced damage to self may occur. The role of the anaphylotoxins and their receptors in further potentiating disease is an area of continued research.

DNA variants that disrupt the normal control of this sequence of events, or that lead to a loss of self-protection from complement activation precipitate the complementmediated renal diseases. Both complement protein deficiency, and normal quantity, abnormal function, protein states have been identified and play a role in aHUS and C3G.

\section{Atypical Hemolytic Uremic Syndrome}

aHUS is the prototypical ultra-rare complement-mediated renal disease. Of the diseases in which complement plays a role, this disease is the one with the greatest likelihood to be driven by a genetic mutation. While the incidence is unknown, it is likely to be on the order of 2 to 5 per million population. ${ }^{5}$ Before the current decade, our limited understanding of the underlying pathology of aHUS meant that it was often a rapidly progressive condition that lead to renal failure and even death-with only marginal response to available therapies. Genetic advances have not only identified causative proteins, but have also laid the groundwork for a targeted, effective treatment strategy.

Genetic mutations are reported to be causal in up to $60 \%$ of aHUS patients. ${ }^{1-3}$ The vast majority of the mutations associated with aHUS occur in heterozygosity, in genes encoding AP regulatory proteins. Complement factor $\mathrm{H}$ gene mutations (CFH) are the most abundant. ${ }^{6-25} \mathrm{FH}$ plays a significant role in protecting host cells from MAC. ${ }^{26-28}$ Found both as a circulating protein and on the host cell surfaces, FH has three major host-cell protective functions. It serves to suppress complement activity on human surfaces by competing with complement FB for binding to $\mathrm{C} 3 \mathrm{~b}$ ( $\boldsymbol{- F i g . ~ 1 )}$ ) and preventing the formation of the $\mathrm{C} 3$ convertase and therefore AP amplification. Once the $\mathrm{C} 3$ convertase is formed, $\mathrm{FH}$ serves to accelerate its decay. Finally, FH functions as a cofactor for complement 
factor I (FI), facilitating cleavage of C3b into its inactive form, iC3b. Disruption of one or more of these roles as a result of mutation may lead to complement-mediated renal disease.

The $C F H$ aHUS mutation database (available at: www.FHHUS.org) indicates that to date $315 \mathrm{CFH}$ mutations have been identified in aHUS patients. $\mathrm{FH}$ is composed of 20 protein subunits or short consensus repeat domains (SCRs) that are encoded by chromosome 1q32 in the regulators of complement gene cluster. While mutations have been identified in several CFH SCRs, the fact that the majority are in the Cterminal end of the protein in aHUS provides an interesting phenotype-genotype correlation. The C-terminus contains the cell-surface binding domain. Binding of $\mathrm{FH}$ to cell-surface glycosaminoglycans via a C-terminus SCR facilitates surface protection from complement activation. A DNA variant that interferes with the cell-surface binding of $\mathrm{FH}$, may directly affect FH ability to protect host cells from complement activity.

The regulators of complement gene region also contain a series of genes known as the complement factor H-related genes (CFHR1-5). While complement regulatory functions have been attributed to the protein products, ${ }^{29-41}$ more study is required to fully understand the role of each gene. One of the clearest roles for pathology in this setting is related to the similarity of these genes to $C F H$. Both $C F H$ and the CFHR genes are made of repeating, homologous elements. The homology makes this region prone to rearrangements from nonhomologous recombination. The impact of recombination depends on the location of the recombination event and the function of the genes involved. The CFHR have far fewer SCR than CFH. During recombination regulatory domains do not match up perfectly or they are completely absent in the CFHR. - Fig. 2 portrays the normal regulators of complement region (-Fig. 2A) and the identified recombination events that have led to fusion proteins (-Fig. 2B-E). The new SCR configuration (fusion gene) leads to a product with altered protein function. If a fusion protein results in an altered $\mathrm{FH}$ function-protection from AP activity may be lost and risk for disease results.

A new role in complement dysregulation has recently been described for the CFHR. It has been demonstrated that the homology of SCRs 1 and 2 of the CFHR1, CFHR2, and CFHR5 genes facilitates the formation of both homodimers and heterodimers. ${ }^{42}$ The heterodimers that have been identified include FHR1-FHR2 and FHR1-FHR5. ${ }^{32,43}$ It has been hypothesized that these dimers bind C3b more effectively the FH yet do not have the same regulatory properties of FH. The functional result of competing with FH binding is an AP that is not regulated normally.

The homozygous deletion of the CFHR3 and CFHR1 genes is not considered a mutation, but is instead a common polymorphism (present in 2-9\% of Europeans, $16 \%$ of Africans, and $\sim 2 \%$ of Chinese ${ }^{44}$ ). However, for unclear reasons, there is a strong association of this genetic change with the production of autoantibodies to $\mathrm{FH}^{2,45-54}$ Around 90 to $95 \%$ of the patients with anti-FH antibodies have a complete deficiency

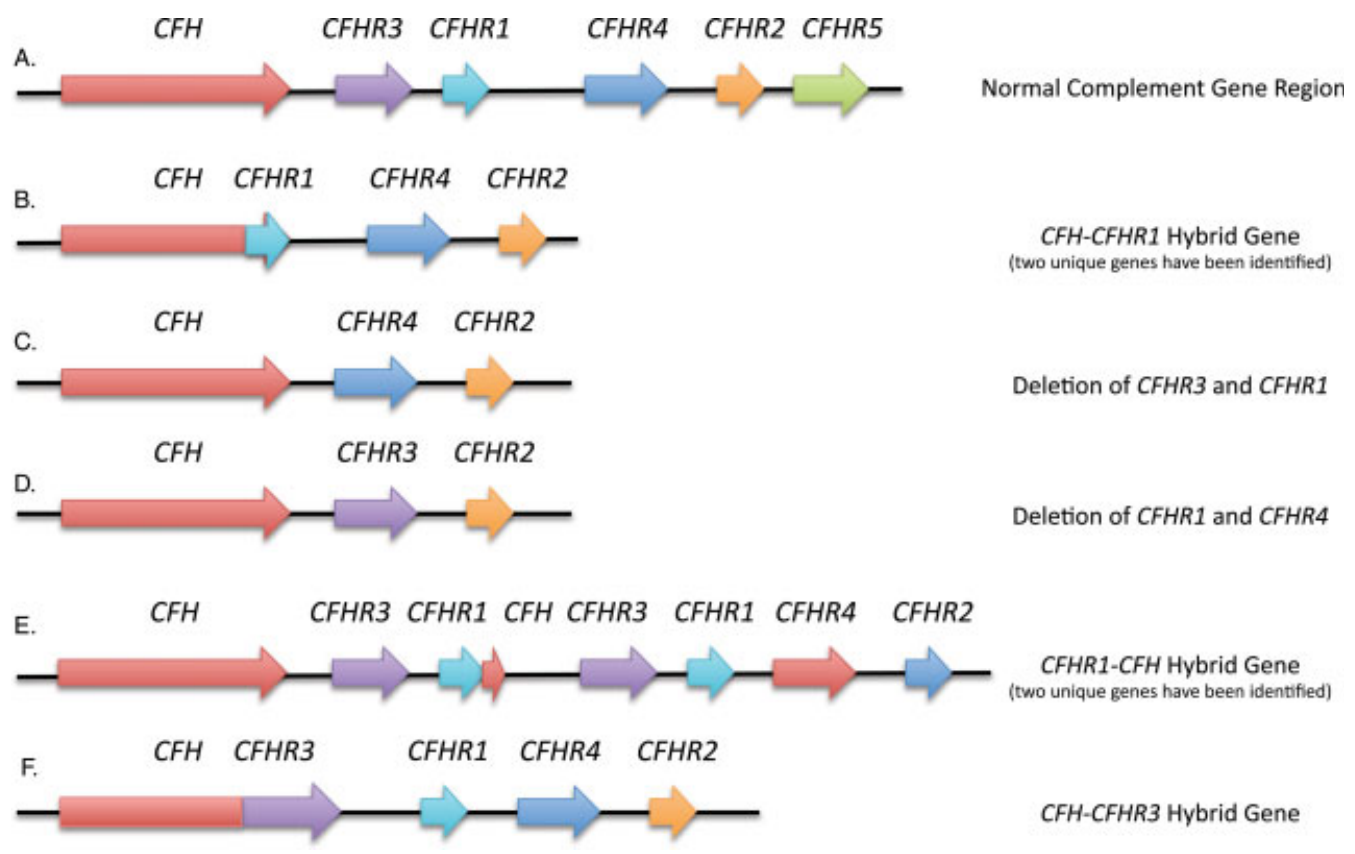

Fig. 2 Abnormal gene arrangements in the CFH-CFHR Region. The five CFHR genes are found in a tandem arrangement on the long arm of chromosome 1. Genomic duplication has led to a high sequence similarity between CFH and the CFHR genes. Sequence homology in turn results in nonallelic homologous recombination events, frequently leading to genomic changes, including deletions, duplications, and rearrangements. The most frequent change is the deletion of CFHR3/CFHR1. Abnormal fusion genes (triggering abnormal protein products) may also result. Nonhomologous recombination events can lead to gene deletions (B, C, D, and F), duplications (E), and hybrid genes (B, E, and F). The functional consequences at the protein level can vary and includes protein deficiency and variable function hybrid proteins. Normal gene sequence (A). CFH, complement factor $\mathrm{H}$; CFHR, complement factor $\mathrm{H}$ related. 
of FH-related proteins 3 (FHR3) and 1 (FHR1). FH autoantibodies interfere with normal FH function and account for up to $8 \%$ of aHUS cases.

In addition to $C F H$ gene mutations are mutations in the complement genes $C F I, C F B, M C P, T H B D$, and $C 3$. FI plays a role in inactivating $\mathrm{C} 3 \mathrm{~b}$ and therefore limiting $\mathrm{C} 3$ convertase activity. Mutations in CFI have been estimated to occur in approximately $8 \%$ of aHUS patients. ${ }^{1-3,53} \mathrm{FB}$ is an integral protein of the $\mathrm{C} 3$ convertase. Mutations in CFB are classically gain-of-function mutations (facilitating an overactive $\mathrm{C} 3$ convertase) and account for about 1 to $4 \%$ of aHUS. ${ }^{1-3,55-58}$ Mutations in membrane cofactor protein (MCP), the gene product of which is a cell-surface complement control protein similar to FH occurs in 5 to $9 \% .^{1-3,59,60}$ Gene mutations in the thrombomodulin gene, the protein product of which is responsible for inactivating the AP anaphylotoxins C3a and C5a have been found in up to $5 \%$ of the aHUS population. ${ }^{1-3}$ $\mathrm{C} 3$, a central AP complement protein may also be abnormal in aHUS. Mutations in C3, like those in CFB are often gain-offunction mutations and occur in 2 to $8 \%$ of the aHUS population. . $^{1-3,53}$

Altogether, these genetic defects result in excessive or amplified activity of the AP, ultimately resulting in the cleavage of $\mathrm{C} 5$. The cleavage of $\mathrm{C} 5$, as described previously, leads to the liberation both of $\mathrm{C} 5 \mathrm{a}$ and of MAC at the endothelial cell surface. As endothelial injury ensues, a complement-mediated thrombotic microangiopathy (TMA) develops, precipitating the risk for the multiorgan dysfunction that is characteristic of severe aHUS.

Defining aHUS as a disease of AP dysregulation has led to the discovery of the first effective pharmaceutical for the treatment of aHUS. Eculizumab, an anti-C5 monoclonal protein that inhibits the cleavage of $\mathrm{C} 5$ can limit the production of $\mathrm{C} 5 \mathrm{~b}$ and the subsequent downstream production of MAC. aHUS provides one of the best examples of how genetic studies have not only provided a clearer understanding of underlying pathology but have also led to a precise treatment strategy. Importantly, inhibition of the cleavage of $\mathrm{C} 5$ has become the most effective treatment for aHUS to date.

The genetic investigation of aHUS patients has also included noncomplement genes. Bu et al have identified several coagulation pathway gene variants in aHUS patients. ${ }^{61}$ They identified abnormalities in the plasminogen gene (the gene that encodes plasminogen, the precursor of plasmin-involved in thrombin lysis) and the ADAMTS13 gene (the gene for the a disintegrin and metalloproteinase with a thrombospondin type 1 motif, member 13 protein $)^{62}$. The discovery of ADAMTS-13 variants in aHUS is interesting as abnormalities in this gene are classically associated with thrombotic thrombocytopenic purpura (TTP). The authors reported that $83 \%$ of the aHUS cohort carried at least one variation of ADAMTS13 and 38\% had multiple ADAMTS-13 variations. Consistent with a possible functional effect of these DNA variations is the fact that aHUS patients have been shown to have reduced levels of ADAMTS-13 during acute disease. The precise role of ADAMTS-13 and plasminogen in aHUS remains to be defined.
The newest gene to be reported in association with aHUS is the gene encoding diacylglycerol kinase-epsilon (DGKE), a protein of the lipid kinase family. ${ }^{63,64}$ This protein is expressed in the endothelium, on platelets and on podocytes. The aHUS clinical picture may be triggered by the activation of protein kinase $C$ secondary to the loss of DGKE function, leading to an upregulation of prothrombotic factors and platelet activation. New evidence suggests that gene abnormalities may facilitate endothelial injury and thus set off a cascade leading to the characteristic TMA of aHUS. ${ }^{65}$

\section{Secondary Thrombotic Microangiopathies}

TMAs other than aHUS are major confounders for the diagnosis of aHUS. Because of the clinical similarity of these diseases with aHUS, it has been hypothesized that a genetic risk also exists for these diseases.

The term TMA is used to refer to any disorder characterized by endothelial cell injury, leading to an arteriolar and capillary thrombosis. The clinical criteria for a TMA include the clinical triad of hemolytic anemia, thrombocytopenia, and organ dysfunction; mainly renal injury or failure. Secondary TMAs are due to several underlying causes, including infection with enterohemorrhagic Escherichia coli, pregnancy, organ transplantation, hematopoietic stem-cell transplant (HSCT), and drugs including calcineurin inhibitors and chemotherapeutics. It remains unclear to what degree genetic abnormalities (particularly in complement genes) play a role in these diseases. Recent studies suggest, for instance, that complement protein abnormalities may indeed be found in the above diseases, however, when genetic investigations have been completed, causal genetic abnormalities have not been found, with very few exceptions ( - Table 1). While it has been hypothesized that there is a genetic predisposition to the other TMAs, this hypothesis requires further study. Below, we discuss briefly what is known about these other rare genetic associations.

TTP is a TMA involving either a deficiency of ADAMTS-13 (a von Willebrand factor cleaving protease) or an inhibitor of ADAMTS-13. ${ }^{66}$ TTP is often easily confused with aHUS or other forms of TMA given the clinical picture of thrombocytopenia, microangiopathic hemolytic anemia, and acute kidney injury. While TTP is most likely to be a disease that results from autoantibody production to ADAMTS-13, in UpshawSchulman, a congenital form of TTP with the same clinical picture, more than 76 mutations have been reported. ${ }^{67}$ of note, along with the primary pathology involving ADAMTS13 , complement activation represented by increased levels of C3a and sMAC have been observed during the acute phase of TTP, however, it has not been proven that this is related to a genetic abnormality. ${ }^{68}$

Infectious TMA associated with clear renal failure (referred to as HUS) most commonly includes HUS due to infection with Shiga toxin producing $E$. coli (ST-HUS) but can also result from infections such as Streptococcus pneumoniae, Shigella, and Campylobacter or viruses including cytomegalovirus, Epstein-Barr virus, and the influenza viruses. While uncommon, complement mutations have been described in ST-HUS patients. ${ }^{69}$ Similarly, three of five patients with pneumococcal 


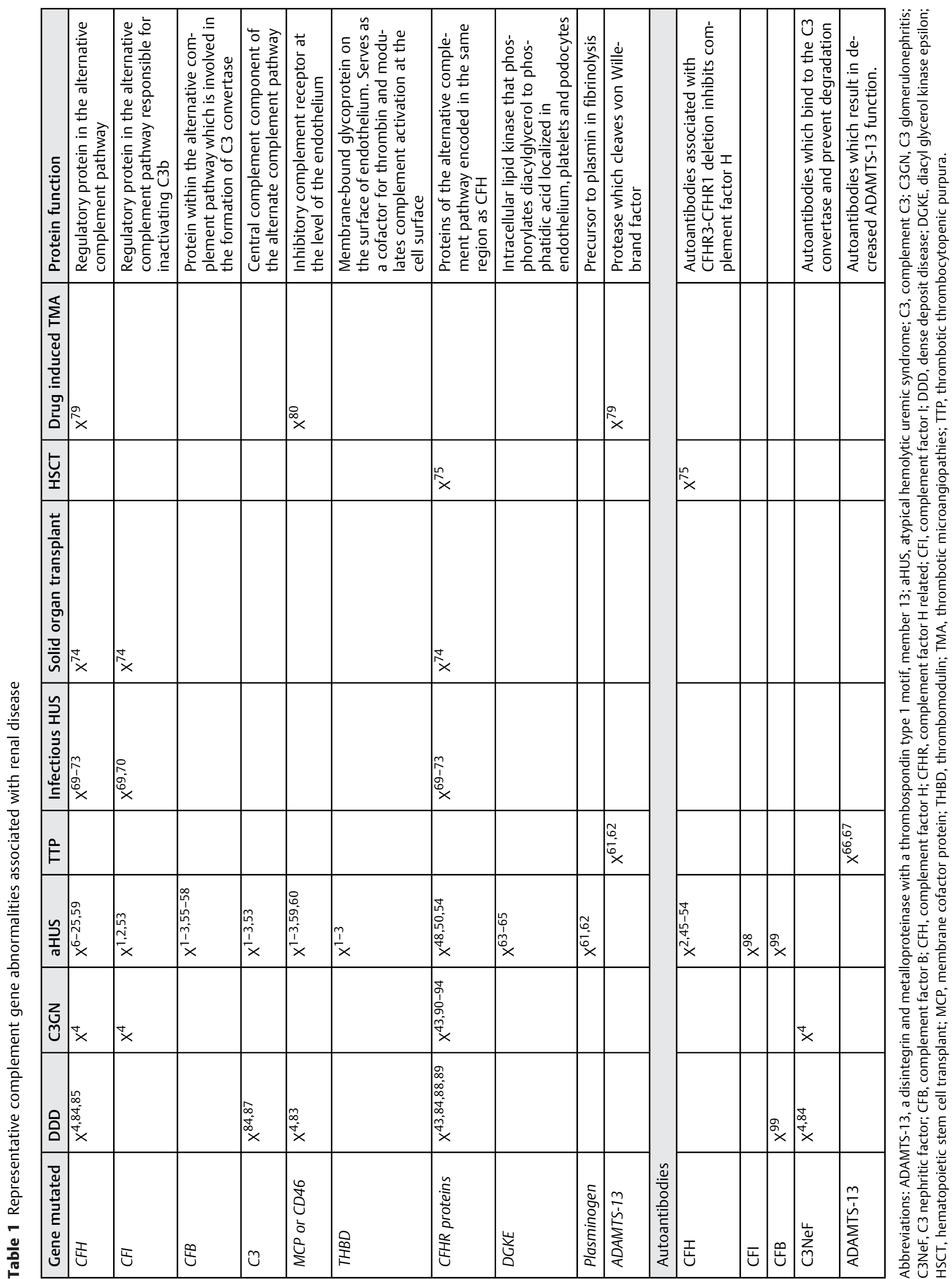


HUS in one cohort carried mutations in the common AP genes CFH, CFI, and in THBD. ${ }^{70}$ Complement mutations in other forms of infectious TMA have also been described, including MCP mutations in influenza A, Bordetella pertussis, and varicella zoster TMA, a CFH mutation in Bordetella TMA and CFH autoantibodies in varicella zoster TMA. ${ }^{71-73}$ The relationship of these gene mutations with causality is unknown.

Complement dysregulation and known mutations in the AP have also been described in solid organ transplant-related TMA. CFH and CFI mutations were identified in $29 \%$ of patients in a cohort of 24 kidney transplant recipients who developed de novo TMA following transplant. ${ }^{74}$ The caveat to interpreting this data are that it remains unclear whether these were previously unidentified aHUS patients and exactly what role the transplant played.

The evidence is less convincing in HSCT-associated TMA. Jodele et al reported that five of six HSCT recipients had a CFHR3-CFHR1 heterozygous gene deletion. While this statistic is interesting, we must keep in mind that the $3 / 1$ deletion is a polymorphism and not a causal DNA change. During the time of their TMA, three patients in their cohort were also found to have $\mathrm{FH}$ autoantibodies-suggesting that their disease was triggered by autoimmune-related complement dysregulation. No patients in the cohort had identifiable mutations in CFI, CFH, MCP, CFB, or CFHR5 genes. ${ }^{75}$

The role of complement in pregnancy-related TMA remains an area of interest. Pregnancy-related TTP cases tend to occur in the second and third trimesters of pregnancy due to a decrease in ADAMTS-13 activity presumably as a result of increased release of VWF toward the end of pregnancy. ${ }^{76}$ Alternatively, $21 \%$ of adult female aHUS patients present during pregnancy with approximately $80 \%$ presenting during the postpartum period. A total of $86 \%$ of these women had identified complement abnormalities. Considering pregnancy and aHUS further, Fakhouri et al reported in their cohort, aHUS was triggered by pregnancy in $20 \%$ of patients with $C F H$ mutations, $28 \%$ with $C 3,11 \%$ with $C F I$, and $17 \%$ with $M C P$ mutations. ${ }^{77}$ More than one mutation was seen in four aHUS patients presenting during pregnancy. TMA during pregnancy has also been linked to verotoxin exposure and vascular endothelial growth factor (VEGF) deficiency. ${ }^{76}$

Many drugs have been reported to cause drug-induced TMA including calcineurin inhibitors, mTOR inhibitors, quinine, chemotherapy agents, VEGF inhibitors, antiplatelet medications, and cocaine. ${ }^{78}$ It has been proposed that druginduced TMA results from an environmental trigger that dysregulates complement in a genetically susceptible host. There have only been a few studies to support this theory. One was a report of four patients with ticlopidine-induced TMA. All four patients were found to be deficient in ADAMTS-13 activity with ADAMTS-13 inhibitors and all four were found to be homozygous or heterozygous for three different $C F H$ polymorphisms, two with known functional significance. ${ }^{79}$ Another report describes a 2-year-old male patient with likely cisplatin-induced TMA who was found to have a heterozygous MCP splice mutation. This patient exhibited clinical improvement with eculizumab therapy. ${ }^{80}$
In the absence of confirmed genetic mutations in the majority of the diseases that make up the secondary TMAs (with the possible exception of pregnancy-associated TMA), it remains impossible to label the majority of TMAs in these settings as genetic-related rare disease.

\section{C3 Glomerulopathy}

C3G is another rare renal disease that involves the abnormal regulation of the AP. In this setting, disease is not manifest by a TMA, but rather the deposition of $\mathrm{C} 3$ breakdown products within the glomeruli of the kidney. The pathological term used to describe this entity is C3-dominant glomerulonephritis ${ }^{81}$ with the disease syndrome being called C3G. C3G includes dense deposit disease (DDD) and C3 glomerulonephritis (C3GN). DDD is diagnosed when linear electron-dense deposits are found within the lamina densa (middle layer) of the glomerular basement membrane on electron microscopy in the setting of a C3-dominant glomerulonephritis. C3GN is used to designate the remainder of cases of $\mathrm{C} 3 \mathrm{G}$ and in general represents those with less dense deposits by electron microscopy. C3GN deposits may involve any combination of mesangial, subepithelial, subendothelial, and less discrete, discontinuous intramembranous deposits. ${ }^{81}$

As with aHUS, C3G is an ultra-rare disease. The incidence of biopsy-proven C3G is estimated to be 1 to 2 per million with equal incidence in both the sexes. ${ }^{82}$ Those affected tend to be children and young adults. ${ }^{82}$ The disease presentation encompasses a spectrum from a relatively mild glomerulonephritis to a severe, rapidly progressive disease that may lead quickly to end-stage kidney disease. There are currently no reliable treatment options for $\mathrm{C} 3 \mathrm{G}$, making this an area ripe for continued genetic and translational research.

While autoimmunity to the C3 convertase (the so called "C3 nephritic factor"-present in up to $85 \%$ of the patients) is believed to be central to disease for the majority of $\mathrm{C} 3 \mathrm{G}$ patients, complement gene abnormalities play a pathological role in C3G also. Servais et al studied a series of 134 patients with idiopathic membranoproliferative glomerulonephritis type I (another form of primary glomerulonephritis, $n=48$ ), $\operatorname{DDD}(n=29)$, and C3GN $(n=56)$. Mutation screening of the complement genes revealed mutations in $\mathrm{CFH}$ in 17 (12.7\%), CFI in $6(4.5 \%)$, and $M C P$ in $1(0.7 \%) .{ }^{4,83}$

DDD more specifically has been shown to be associated with mutations in $C 3, C F H$, and the CFHR genes. ${ }^{84}$ Five of 29 DDD patients were reported to have mutations within the CFH gene in the 2012 Servais et al study. ${ }^{4}$ One of which had been described previously in aHUS. ${ }^{85}$ Martinez-Barricarte et al identified a gain-of-function $\mathrm{C} 3$ mutation in a familial case of $\mathrm{C} 3 \mathrm{G} .{ }^{86}$ The authors demonstrated that the $\mathrm{C} 3$ mutation conferred resistance to AP regulation. Abrera-Abeleda et al have identified complement gene mutations in 66 patients with biopsy-proven DDD. ${ }^{87}$ In addition, in this cohort, the authors identified four novel sequence variants in ADAMTS19 (another member of the disintegrin and metalloprotease family), C3aR1 (complement component 3a receptor), CR1 (complement receptor type 1 ), and $C 3$. The functional significance of the latter gene findings is unknown. 
As in aHUS, the FHR proteins play a role in the pathogenesis of DDD. ${ }^{43} \mathrm{~A}$ familial mutation in CFHR1 was found to result in the duplication of the N-terminus SCR domains. The result was a mutant FHR1 protein, capable of forming unusually large multimeric complexes. These complexes exhibited competition with FH and led to dysregulation of the $\mathrm{AP}^{43}$ Similarly, Chen et al described a chromosomal deletion in the CFHR gene cluster in familial DDD which resulted in a FHR2FHR5 hybrid protein capable of stabilizing the $\mathrm{C} 3$ convertase, and reducing FH-mediated decay. ${ }^{88}$ CFHR5 polymorphisms have been described in DDD, however, the functional significance of these polymorphisms remains unclear. ${ }^{89}$

Similar gene abnormalities are also present in the C3GN form of C3G. In the Servais et al study, 7 of 56 patients with C3GN diagnosed by biopsy were identified to have $\mathrm{CFH}$ mutations. ${ }^{4}$ Additionally, three of the C3GN patients were found to have mutations in CFI, all of which had been previously described in aHUS and one patient with a mutation in MCP. ${ }^{4}$

The CFHR genes also play a role in C3GN. Gale et al were the first to report on CFHR5 nephropathy, an autosomal dominant familial C3G in patients of Cypriot descent. The authors identified an internal duplication of exons 2 and 3 of CFHR5 which segregated with a C3-dominant glomerulonephritis on biopsy. ${ }^{90,91} \mathrm{~A}$ familial C3GN involving CFHR5 in families of non-Cypriot descent has also been identified. ${ }^{92}$

The homology in the CFHR region plays a role in the C3GN setting. ${ }^{93} \mathrm{~A}$ familial case of C3G highlighted a rearrangement within the CFHR locus resulting in a hybrid CFHR3-CFHR1 gene whose product appeared to have a competitive function with FH. ${ }^{94}$ Another case study identified a CFHR1 duplication, capable of forming multimers with enhanced binding of CFHR1 to C3b, iC3b and C3 dg, thus altering normal AP activity. ${ }^{43}$

In the absence of overt genetic mutation in some (particularly DDD patients), the data support the presence of a "complotype." ${ }^{87,95-97}$ The complotype is an inherited set of common polymorphisms in complement proteins that predict susceptibility to inflammatory or infectious diseases. These are not mutations but are rather risk factors for the development of the disease. There is evidence that they have an impact on susceptibility to inflammatory and infectious disease.

\section{Conclusion}

Here, we provide a comprehensive review of the contribution of genetics to our understanding of complement-mediated renal disease. Additional genetic discoveries are sure to follow, however, it is clear that the genetics of complement are becoming the key to both accurate diagnosis and targeted therapy for these rare, previously untreatable diseases. This set of diseases provides a clear example of the power of genetics in improving the outcome of patients with rare disease.

Note

Dr. Nester is supported by the Stead Family Department of Pediatrics, University of Iowa.
Conflict of Interest

None.

\section{References}

1 Maga TK, Nishimura CJ, Weaver AE, Frees KL, Smith RJ. Mutations in alternative pathway complement proteins in American patients with atypical hemolytic uremic syndrome. Hum Mutat 2010; 31(6):E1445-E1460

2 Fremeaux-Bacchi V, Fakhouri F, Garnier A, et al. Genetics and outcome of atypical hemolytic uremic syndrome: a nationwide French series comparing children and adults. Clin J Am Soc Nephrol 2013;8(4):554-562

3 Noris M, Caprioli J, Bresin E, et al. Relative role of genetic complement abnormalities in sporadic and familial aHUS and their impact on clinical phenotype. Clin J Am Soc Nephrol 2010; 5(10):1844-1859

4 Servais A, Noël LH, Roumenina LT, et al. Acquired and genetic complement abnormalities play a critical role in dense deposit disease and other C3 glomerulopathies. Kidney Int 2012;82(4): 454-464

5 Loirat C, Frémeaux-Bacchi V. Atypical hemolytic uremic syndrome. Orphanet J Rare Dis 2011;6:60

6 Ault BH, Schmidt BZ, Fowler NL, et al. Human factor H deficiency. Mutations in framework cysteine residues and block in $\mathrm{H}$ protein secretion and intracellular catabolism. J Biol Chem 1997;272(40): 25168-25175

7 Buddles MR, Donne RL, Richards A, Goodship J, Goodship TH. Complement factor $\mathrm{H}$ gene mutation associated with autosomal recessive atypical hemolytic uremic syndrome. Am J Hum Genet 2000;66(5):1721-1722

8 Caprioli J, Bettinaglio P, Zipfel PF, et al; Itaslian Registry of Familial and Recurrent HUS/TTP. The molecular basis of familial hemolytic uremic syndrome: mutation analysis of factor $\mathrm{H}$ gene reveals a hot spot in short consensus repeat 20. J Am Soc Nephrol 2001;12(2): 297-307

9 Caprioli J, Castelletti F, Bucchioni S, et al; International Registry of Recurrent and Familial HUS/TTP. Complement factor H mutations and gene polymorphisms in haemolytic uraemic syndrome: the C257T, the A2089G and the G2881T polymorphisms are strongly associated with the disease. Hum Mol Genet 2003;12(24): 3385-3395

10 Filler G, Radhakrishnan S, Strain L, Hill A, Knoll G, Goodship TH. Challenges in the management of infantile factor $\mathrm{H}$ associated hemolytic uremic syndrome. Pediatr Nephrol 2004;19(8): 908-911

11 Guigonis V, Frémeaux-Bacchi V, Giraudier S, et al. Late-onset thrombocytic microangiopathy caused by cblC disease: association with a factor $\mathrm{H}$ mutation. Am J Kidney Dis 2005;45(3): 588-595

12 Heinen S, Sanchez-Corral P, Jackson MS, et al. De novo gene conversion in the RCA gene cluster (1q32) causes mutations in complement factor $\mathrm{H}$ associated with atypical hemolytic uremic syndrome. Hum Mutat 2006;27(3):292-293

13 Heinen S, Józsi M, Hartmann A, et al. Hemolytic uremic syndrome: a factor $\mathrm{H}$ mutation (E1172Stop) causes defective complement control at the surface of endothelial cells. J Am Soc Nephrol 2007; 18(2):506-514

14 Licht C, Heinen S, Józsi M, et al. Deletion of Lys224 in regulatory domain 4 of Factor $\mathrm{H}$ reveals a novel pathomechanism for dense deposit disease (MPGN II). Kidney Int 2006;70(1):42-50

15 Manuelian T, Hellwage J, Meri S, et al. Mutations in factor $\mathrm{H}$ reduce binding affinity to $\mathrm{C} 3 \mathrm{~b}$ and heparin and surface attachment to endothelial cells in hemolytic uremic syndrome. J Clin Invest 2003; 111(8):1181-1190 
16 Neumann HP, Salzmann M, Bohnert-Iwan B, et al. Haemolytic uraemic syndrome and mutations of the factor $H$ gene: a registrybased study of German speaking countries. J Med Genet 2003; 40(9):676-681

17 Noris M, Bucchioni S, Galbusera M, et al; International Registry of Recurrent and Familial HUS/TTP. Complement factor $\mathrm{H}$ mutation in familial thrombotic thrombocytopenic purpura with ADAMTS13 deficiency and renal involvement. J Am Soc Nephrol 2005;16(5): 1177-1183

18 Pérez-Caballero D, González-Rubio C, Gallardo ME, et al. Clustering of missense mutations in the $\mathrm{C}$-terminal region of factor $\mathrm{H}$ in atypical hemolytic uremic syndrome. Am J Hum Genet 2001; 68(2):478-484

19 Richards A, Buddles MR, Donne RL, et al. Factor $\mathrm{H}$ mutations in hemolytic uremic syndrome cluster in exons 18-20, a domain important for host cell recognition. Am J Hum Genet 2001;68(2): 485-490

20 Rodríguez de Córdoba S, Hidalgo MS, Pinto S, Tortajada A. Genetics of atypical hemolytic uremic syndrome (aHUS). Semin Thromb Hemost 2014;40(4):422-430

21 Sánchez-Corral P, Bellavia D, Amico L, Brai M, Rodríguez de Córdoba S. Molecular basis for factor $\mathrm{H}$ and FHL-1 deficiency in an Italian family. Immunogenetics 2000;51(4-5):366-369

22 Sánchez-Corral P, Pérez-Caballero D, Huarte O, et al. Structural and functional characterization of factor $\mathrm{H}$ mutations associated with atypical hemolytic uremic syndrome. Am J Hum Genet 2002; 71(6):1285-1295

23 Vaziri-Sani F, Holmberg L, Sjöholm AG, et al. Phenotypic expression of factor $\mathrm{H}$ mutations in patients with atypical hemolytic uremic syndrome. Kidney Int 2006;69(6):981-988

24 Warwicker P, Goodship TH, Donne RL, et al. Genetic studies into inherited and sporadic hemolytic uremic syndrome. Kidney Int 1998;53(4):836-844

25 Ying L, Katz Y, Schlesinger M, et al. Complement factor $\mathrm{H}$ gene mutation associated with autosomal recessive atypical hemolytic uremic syndrome. Am J Hum Genet 1999;65(6): 1538-1546

26 Schmidt CQ, Herbert AP, Kavanagh D, et al. A new map of glycosaminoglycan and $\mathrm{C} 3 \mathrm{~b}$ binding sites on factor $\mathrm{H}$. J Immunol 2008;181(4):2610-2619

27 Clark SJ, Ridge LA, Herbert AP, et al. Tissue-specific host recognition by complement factor $\mathrm{H}$ is mediated by differential activities of its glycosaminoglycan-binding regions. J Immunol 2013; 190(5):2049-2057

28 Rodríguez de Córdoba S, Esparza-Gordillo J, Goicoechea de Jorge E, Lopez-Trascasa M, Sánchez-Corral P. The human complement factor $\mathrm{H}$ : functional roles, genetic variations and disease associations. Mol Immunol 2004;41(4):355-367

29 Heinen S, Hartmann A, Lauer N, et al. Factor H-related protein 1 (CFHR-1) inhibits complement C5 convertase activity and terminal complex formation. Blood 2009;114(12):2439-2447

30 Timmann C, Leippe M, Horstmann RD. Two major serum components antigenically related to complement factor $\mathrm{H}$ are different glycosylation forms of a single protein with no factor $\mathrm{H}$-like complement regulatory functions. J Immunol 1991;146(4): 1265-1270

31 Fritsche LG, Chen W, Schu M, et al; AMD Gene Consortium. Seven new loci associated with age-related macular degeneration. Nat Genet 2013;45(4):433-439, e1-e2

32 Goicoechea de Jorge E, Caesar JJ, Malik TH, et al. Dimerization of complement factor $\mathrm{H}$-related proteins modulates complement activation in vivo. Proc Natl Acad Sci U S A 2013;110(12): 4685-4690

33 Eberhardt HU, Buhlmann D, Hortschansky P, et al. Human factor $\mathrm{H}$ related protein 2 (CFHR2) regulates complement activation. PLoS ONE 2013;8(11):e78617

34 Hellwage J, Jokiranta TS, Koistinen V, Vaarala O, Meri S, Zipfel PF. Functional properties of complement factor $\mathrm{H}$-related proteins
FHR-3 and FHR-4: binding to the C3d region of C3b and differential regulation by heparin. FEBS Lett 1999;462(3):345-352

35 Hebecker M, Okemefuna AI, Perkins SJ, Mihlan M, Huber-Lang M, Józsi M. Molecular basis of C-reactive protein binding and modulation of complement activation by factor $\mathrm{H}$-related protein 4 . Mol Immunol 2010;47(6):1347-1355

36 Mihlan M, Hebecker M, Dahse HM, et al. Human complement factor $\mathrm{H}$-related protein 4 binds and recruits native pentameric $\mathrm{C}$ reactive protein to necrotic cells. Mol Immunol 2009;46(3): 335-344

37 McRae JL, Duthy TG, Griggs KM, et al. Human factor H-related protein 5 has cofactor activity, inhibits C3 convertase activity, binds heparin and C-reactive protein, and associates with lipoprotein. J Immunol 2005;174(10):6250-6256

38 Venables JP, Strain L, Routledge D, et al. Atypical haemolytic uraemic syndrome associated with a hybrid complement gene. PLoS Med 2006;3(10):e431

39 Nester C, Stewart Z, Myers D, et al. Pre-emptive eculizumab and plasmapheresis for renal transplant in atypical hemolytic uremic syndrome. Clin J Am Soc Nephrol 2011;6(6):1488-1494

40 Maga TK, Meyer NC, Belsha C, Nishimura CJ, Zhang Y, Smith RJ. A novel deletion in the RCA gene cluster causes atypical hemolytic uremic syndrome. Nephrol Dial Transplant 2011;26(2):739-741

41 Krid S, Roumenina LT, Beury D, et al. Renal transplantation under prophylactic eculizumab in atypical hemolytic uremic syndrome with CFH/CFHR1 hybrid protein. Am J Transplant 2012;12(7): 1938-1944

42 Barbour TD, Ruseva MM, Pickering MC. Update on C3 glomerulopathy. Nephrol Dial Transplant 2014

43 Tortajada A, Yébenes H, Abarrategui-Garrido C, et al. C3 glomerulopathy-associated CFHR1 mutation alters FHR oligomerization and complement regulation. J Clin Invest 2013;123(6):2434-2446

44 Leban N, Abarrategui-Garrido C, Fariza-Requejo E, et al. Factor H and CFHR1 polymorphisms associated with atypical Haemolytic Uraemic Syndrome (aHUS) are differently expressed in Tunisian and in Caucasian populations. Int J Immunogenet 2012;39(2): 110-113

45 Zipfel PF, Mache C, Müller D, Licht C, Wigger M, Skerka C; European DEAP-HUS Study Group. DEAP-HUS: deficiency of CFHR plasma proteins and autoantibody-positive form of hemolytic uremic syndrome. Pediatr Nephrol 2010;25(10):2009-2019

46 Józsi M, Heinen S, Hartmann $\mathrm{A}$, et al. Factor $\mathrm{H}$ and atypical hemolytic uremic syndrome: mutations in the C-terminus cause structural changes and defective recognition functions. J Am Soc Nephrol 2006;17(1):170-177

47 Józsi M, Strobel S, Dahse HM, et al. Anti factor H autoantibodies block C-terminal recognition function of factor $\mathrm{H}$ in hemolytic uremic syndrome. Blood 2007;110(5):1516-1518

48 Dragon-Durey MA, Blanc C, Marliot F, et al. The high frequency of complement factor $\mathrm{H}$ related CFHR1 gene deletion is restricted to specific subgroups of patients with atypical haemolytic uraemic syndrome. J Med Genet 2009;46(7):447-450

49 Skerka C, Józsi M, Zipfel PF, Dragon-Durey MA, Fremeaux-Bacchi V. Autoantibodies in haemolytic uraemic syndrome (HUS). Thromb Haemost 2009;101(2):227-232

50 Zipfel PF, Edey M, Heinen S, et al. Deletion of complement factor Hrelated genes CFHR1 and CFHR3 is associated with atypical hemolytic uremic syndrome. PLoS Genet 2007;3(3):e41

51 Dragon-Durey MA, Loirat C, Cloarec S, et al. Anti-Factor H autoantibodies associated with atypical hemolytic uremic syndrome. J Am Soc Nephrol 2005;16(2):555-563

52 Józsi M, Licht C, Strobel S, et al. Factor $\mathrm{H}$ autoantibodies in atypical hemolytic uremic syndrome correlate with CFHR1/CFHR3 deficiency. Blood 2008;111(3):1512-1514

53 Bienaime F, Dragon-Durey MA, Regnier $\mathrm{CH}$, et al. Mutations in components of complement influence the outcome of Factor Iassociated atypical hemolytic uremic syndrome. Kidney Int 2010; 77(4):339-349 
54 Moore I, Strain L, Pappworth I, et al. Association of factor $\mathrm{H}$ autoantibodies with deletions of CFHR1, CFHR3, CFHR4, and with mutations in $\mathrm{CFH}, \mathrm{CFI}, \mathrm{CD} 46$, and C3 in patients with atypical hemolytic uremic syndrome. Blood 2010;115(2):379-387

55 Tawadrous H, Maga T, Sharma J, Kupferman J, Smith RJ, Schoeneman M. A novel mutation in the complement factor B gene (CFB) and atypical hemolytic uremic syndrome. Pediatr Nephrol 2010; 25(5):947-951

56 Goicoechea de Jorge E, Harris CL, Esparza-Gordillo J, et al. Gain-offunction mutations in complement factor $B$ are associated with atypical hemolytic uremic syndrome. Proc Natl Acad Sci U S A 2007;104(1):240-245

57 Frémeaux-Bacchi V, Miller EC, Liszewski MK, et al. Mutations in complement C3 predispose to development of atypical hemolytic uremic syndrome. Blood 2008;112(13):4948-4952

58 Roumenina LT, Jablonski M, Hue C, et al. Hyperfunctional C3 convertase leads to complement deposition on endothelial cells and contributes to atypical hemolytic uremic syndrome. Blood 2009;114(13):2837-2845

59 Caprioli J, Noris M, Brioschi S, et al; International Registry of Recurrent and Familial HUS/TTP. Genetics of HUS: the impact of MCP, CFH, and IF mutations on clinical presentation, response to treatment, and outcome. Blood 2006;108(4):1267-1279

60 Westra D, Vernon KA, Volokhina EB, Pickering MC, van de Kar NC, van den Heuvel LP. Atypical hemolytic uremic syndrome and genetic aberrations in the complement factor $\mathrm{H}$-related 5 gene. J Hum Genet 2012;57(7):459-464

61 Bu F, Maga T, Meyer NC, et al. Comprehensive genetic analysis of complement and coagulation genes in atypical hemolytic uremic syndrome. J Am Soc Nephrol 2014;25(1):55-64

62 Bu F, Borsa NG, Jones MB, et al. High-Throughput Genetic Testing for Thrombotic Microangiopathies and C3 Glomerulopathies. J Am Soc Nephrol 2015

63 Lemaire M, Frémeaux-Bacchi V, Schaefer F, et al. Recessive mutations in DGKE cause atypical hemolytic-uremic syndrome. Nat Genet 2013;45(5):531-536

64 Lee JW. Early infantile onset of atypical hemolytic-uremic syndrome is caused by recessive mutations in DGKE. Clin Genet 2013; 84(4):342-343

65 Bruneau S, Néel M, Roumenina LT, et al. Loss of DGKe induces endothelial cell activation and death independently of complement activation. Blood 2015;125(6):1038-1046

66 Zafrani L, Mariotte E, Darmon M, et al. Acute renal failure is prevalent in patients with thrombotic thrombocytopenic purpura associated with low plasma ADAMTS13 activity. J Thromb Haemost 2015;13(3):380-389 PubMed

67 Lotta LA, Garagiola I, Palla R, Cairo A, Peyvandi F. ADAMTS13 mutations and polymorphisms in congenital thrombotic thrombocytopenic purpura. Hum Mutat 2010;31(1):11-19

68 Réti M, Farkas P, Csuka D, et al. Complement activation in thrombotic thrombocytopenic purpura. J Thromb Haemost 2012;10(5): 791-798

69 Alberti M, Valoti E, Piras R, et al. Two patients with history of STECHUS, posttransplant recurrence and complement gene mutations. Am J Transplant 2013;13(8):2201-2206

70 Szilágyi A, Kiss N, Bereczki C, et al. The role of complement in Streptococcus pneumoniae-associated haemolytic uraemic syndrome. Nephrol Dial Transplant 2013;28(9):2237-2245

71 Bento D, Mapril J, Rocha C, et al. Triggering of atypical hemolytic uremic syndrome by influenza A (H1N1). Ren Fail 2010;32(6): 753-756

72 Obando I, Camacho MS, Falcon-Neyra D, Hurtado-Mingo A, Neth O. Atypical hemolytic uremic syndrome associated with Bordetella pertussis infection. Pediatr Infect Dis J 2012;31(11):1210

73 Kwon T, Belot A, Ranchin B, et al. Varicella as a trigger of atypical haemolytic uraemic syndrome associated with complement dys- function: two cases. Nephrol Dial Transplant 2009;24(9): 2752-2754

74 Le Quintrec M, Lionet A, Kamar N, et al. Complement mutationassociated de novo thrombotic microangiopathy following kidney transplantation. Am J Transplant 2008;8(8):1694-1701

75 Jodele S, Licht C, Goebel J, et al. Abnormalities in the alternative pathway of complement in children with hematopoietic stem cell transplant-associated thrombotic microangiopathy. Blood 2013; 122(12):2003-2007

76 Fakhouri F, Vercel C, Frémeaux-Bacchi V. Obstetric nephrology: AKI and thrombotic microangiopathies in pregnancy. Clin J Am Soc Nephrol 2012;7(12):2100-2106

77 Fakhouri F, Roumenina L, Provot F, et al. Pregnancy-associated hemolytic uremic syndrome revisited in the era of complement gene mutations. J Am Soc Nephrol 2010;21(5):859-867

78 Riedl M, Fakhouri F, Le Quintrec M, et al. Spectrum of complementmediated thrombotic microangiopathies: pathogenetic insights identifying novel treatment approaches. Semin Thromb Hemost 2014;40(4):444-464

79 Chapin J, Eyler S, Smith R, Tsai HM, Laurence J. Complement factor $\mathrm{H}$ mutations are present in ADAMTS13-deficient, ticlopidineassociated thrombotic microangiopathies. Blood 2013;121(19): 4012-4013

80 Gilbert RD, Stanley LK, Fowler DJ, Angus EM, Hardy SA, Goodship TH. Cisplatin-induced haemolytic uraemic syndrome associated with a novel intronic mutation of CD46 treated with eculizumab. Clin Kidney J 2013;6(4):421-425

81 Pickering MC, D'Agati VD, Nester CM, et al. C3 glomerulopathy: consensus report. Kidney Int 2013;84(6):1079-1089

82 Medjeral-Thomas NR, O'Shaughnessy MM, O'Regan JA, et al. C3 glomerulopathy: clinicopathologic features and predictors of outcome. Clin J Am Soc Nephrol 2014;9(1):46-53

83 Xiao X, Pickering MC, Smith RJ. C3 glomerulopathy: the genetic and clinical findings in dense deposit disease and C3 glomerulonephritis. Semin Thromb Hemost 2014;40(4):465-471

84 Zhang Y, Meyer NC, Wang K, et al. Causes of alternative pathway dysregulation in dense deposit disease. Clin J Am Soc Nephrol 2012;7(2):265-274

85 Sellier-Leclerc AL, Fremeaux-Bacchi V, Dragon-Durey MA, et al; French Society of Pediatric Nephrology. Differential impact of complement mutations on clinical characteristics in atypical hemolytic uremic syndrome. J Am Soc Nephrol 2007;18(8):2392-2400

86 Martínez-Barricarte R, Heurich M, Valdes-Cañedo F, et al. Human C3 mutation reveals a mechanism of dense deposit disease pathogenesis and provides insights into complement activation and regulation. J Clin Invest 2010;120(10):3702-3712

87 Abrera-Abeleda MA, Nishimura C, Frees K, et al. Allelic variants of complement genes associated with dense deposit disease. J Am Soc Nephrol 2011;22(8):1551-1559

88 Chen Q Wiesener M, Eberhardt HU, et al. Complement factor Hrelated hybrid protein deregulates complement in dense deposit disease. J Clin Invest 2014;124(1):145-155

89 Abrera-Abeleda MA, Nishimura C, Smith JL, et al. Variations in the complement regulatory genes factor $\mathrm{H}(\mathrm{CFH})$ and factor $\mathrm{H}$ related 5 (CFHR5) are associated with membranoproliferative glomerulonephritis type II (dense deposit disease). J Med Genet 2006;43(7): 582-589

90 Gale DP, de Jorge EG, Cook HT, et al. Identification of a mutation in complement factor H-related protein 5 in patients of Cypriot origin with glomerulonephritis. Lancet 2010;376(9743):794-801

91 Athanasiou Y, Voskarides K, Gale DP, et al. Familial C3 glomerulopathy associated with CFHR5 mutations: clinical characteristics of 91 patients in 16 pedigrees. Clin J Am Soc Nephrol 2011;6(6):1436-1446

92 Medjeral-Thomas N, Malik TH, Patel MP, et al. A novel CFHR5 fusion protein causes C3 glomerulopathy in a family without Cypriot ancestry. Kidney Int 2014;85(4):933-937 
93 Skerka C, Chen Q, Fremeaux-Bacchi V, Roumenina LT. Complement factor H related proteins (CFHRs). Mol Immunol 2013;56(3):170-180

94 Malik TH, Lavin PJ, Goicoechea de Jorge E, et al. A hybrid CFHR3-1 gene causes familial C3 glomerulopathy. J Am Soc Nephrol 2012; 23(7):1155-1160

95 Harris CL, Heurich M, Rodriguez de Cordoba S, Morgan BP. The complotype: dictating risk for inflammation and infection. Trends Immunol 2012;33(10):513-521

96 Lay E, Nutland S, Smith JE, et al. Complotype affects the extent of down-regulation by Factor I of the $\mathrm{C} 3 \mathrm{~b}$ feedback cycle in vitro. Clin Exp Immunol 2015;181(2):314-322
97 Heurich M, Martínez-Barricarte R, Francis NJ, et al. Common polymorphisms in $\mathrm{C} 3$, factor $\mathrm{B}$, and factor $\mathrm{H}$ collaborate to determine systemic complement activity and disease risk. Proc Natl Acad Sci U S A 2011;108(21):8761-8766

98 Kavanagh D, Pappworth IY, Anderson H, et al. Factor I autoantibodies in patients with atypical hemolytic uremic syndrome: disease-associated or an epiphenomenon? Clin J Am Soc Nephrol 2012;7(3):417-426

99 Strobel S, Zimmering M, Papp K, Prechl J, Józsi M. Anti-factor B autoantibody in dense deposit disease. Mol Immunol 2010; 47(7-8):1476-1483 